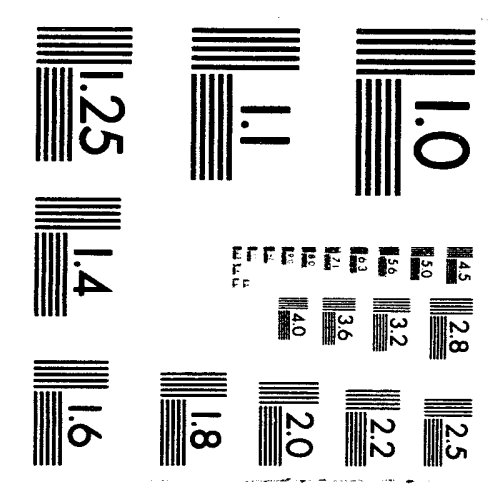




\title{
Development of Dry Barriers for Containment and Remediation at Waste Sites
}

\author{
Bruce M. Thomson ${ }^{1}$ \\ Carl E. Morris 1 \\ John Stormont ${ }^{2}$ \\ Mark D. Ankeny ${ }^{3}$
}

\begin{abstract}
This paper describes a concept in which dry air is injected into an unsaturated formation to reduce the soil moisture content, referred to here as a dry (or sometimes tensiometric) barrier. The objective is to reduce the hydraulic conductivity of the unsaturated media to the point where liquid phase transport becomes negligible, thereby achieving containment. The concept could be applied in subsurface formations to provide containment from a leaking facility, or it could be incorporated into a cover design to provide redundancy for a capillary barrier. The air injection process could in principle be coupled with a vacuum extraction system to recover soil vapors, which would then provide a remediation process that would be appropriate if volatile organic compounds were present.
\end{abstract}

Work to date has consisted of a combined theoretical, laboratory, and field research investigation. The objective of this research was to demonstrate the technical feasibility of the dry barrier concept by identifying the parameters which determine its effectiveness. Based on the results obtained for the experimental and theoretical studies, feasibility analyses were prepared for as a modification for a landfill cover design to prevent infiltration from atmospheric precipitation and for potential application of dry barriers to achieve subsurface containment and removal of volatile constituents. These analyses considered the technical as well as the economic aspects of the dry barrier concept.

\section{INTRODUCTION}

Remediation activities that take place following release of a contaminant to the soil environment may be broken into one of the following categories of actions: containment, removal of contaminated soils, removal of mobile constituents, or in-situ stabilization or degradation of the contaminants. Often two or more of these actions may be required to completely remediate a contaminated site as with a leaking underground storage tank where excavation and disposal of contaminated soil might be accompanied by free product recovery, vapor extraction, and in-situ biological degradation. Current containment and remediation technologies are increasingly effective under conditions of shallow depth to groundwater. However, there remains a need for containment and remediation alternatives at sites where there is an extensive vadose zone underlying the pollutant source, where contaminant migration cannot be controlled by conventional hydraulic means.

At the opposite end of the remediation spectrum, there is a continuing need for development of improved landfill cover designs which play an important role in limiting downward movement of meteoric water through waste disposal facilities. Conventional covers can vary from a simple soil cover to multiple layers of earthen materials and geosynthetic materials, depending upon applicable regulations, risks associated with the waste materials, and conventional practice in a particular industry. Conventional designs featuring a soil layer often suffer from desiccation, root and animal intrusion, differential settling, and other phenomena which affect their integrity.

1Department of Civil Engineering, University of New Mexico, Albuquerque, NM 87131

2Sandia National Laboratories, P.O. Box 5800, Albuquerque, NM 87185

3Daniel B. Stephens \& Associates, 6020 Academy NE, Albuquerque, NM 87109 
Geosynthetics, increasingly used in current cover designs, do not address all of the shortcomings of layered soil barriers and can add substantially to the cost of the cover system. Alternative designs such as capillary barriers show promise, but they are still in an early stage of development.

This paper describes development of a dry barrier concept for potential application in subsurface containment and remediation activities, or as an additional component of a landfill cover system. A dry barrier is a layer of geologic material whose moisture content is reduced to very low values by circulating dry air through it. Drying a soil layer creates a barrier to water movement in three ways. First, the drying removes water from the system, intercepting the downward movement of water. Second, drying a soil layer increases its water storage capacity so the soil will tend to retain rather than transmit water. Third, as a soil layer dries, progressively smaller and smaller pores empty and hydraulic conductivity of the formation for liquid flow decreases. For example, the hydraulic conductivity of a typical sand may decrease three orders of magnitude as its moisture content is reduced from 20 to $10 \%$. The coarser a soil layer is, the greater the reduction in its hydraulic conductivity as it dries, therefore, an ideal application would include a stratigraphic section with sand or gravel materials.

\section{THEORETICAL CONSIDERATIONS}

The flow of water in unsaturated soils differs from that of saturated soils due to the presence of a gas phas (air) and negative liquid pressures (suction) resulting from surface tension effects. Unsaturated flow occurs through only a portion of the pores that are present, hence, liquids must flow through more constrained and tortuous channels (1). Like saturated flow, water movement through unsaturated porous media is governed by the potential gradient and the geometric properties of the pore channels. In unsaturated conditions, the flow of water is driven by the potential gradient which is produced by negative liquid pressures (suction) and water flows from areas of low matric suction or potential to areas of higher potential, which is down gradient (2).

Flow in unsaturated media is described by the Buckingham-Darcy flux law, which is a modification to the well known Darcy equation. The Buckingham-Darcy flux law for vertical water flux $\left(J_{W}\right)$ is:

$$
J_{w}=-K(\psi)\left(\frac{\partial h}{\partial z}+1\right)
$$

$\mathrm{K}$ is the unsaturated hydraulic conductivity, $\mathrm{h}$ is the soil water potential head, $\psi=\rho \mathrm{gh}$ is the soil water potential, $\rho$ is the density of water, $g$ is the gravitational constant, and $z$ is elevation. Equation (1) shows that the hydraulic conductivity $(\mathrm{K})$ of an unsaturated soil is a function of the soil water potential. As soil water potential increases, conductivity decreases in a non-linear fashion. The function that relates conductivity to matric potential is dependent on the soil type and pore size and pore size distribution. In general, the hydraulic conductivity of a coarse or sandy soil decreases much more rapidly than that of a fine grained or clay rich soil and at some point may be greater.

The moisture content $(\theta)$ of a porous medium is also a function of matric potential and like hydraulic conductivity, it decreases non-linearly as suction increases. Because matric potential can be mapped into moisture content, hydraulic conductivity can also be described as a function of moisture content. Van Genuchten (3) describes several of the empirical equations that are commonly used to describe the relationships between head, moisture content and hydraulic conductivity.

\section{DISCLAIMER}

This report was prepared as an account of work sponsored by an agency of the United Siates Government. Neither the United States Government nor any agency thereof, nor any of their employees, makes any warranty, express or implied, or assumes any legal liability or responsibility for the accuracy, completeness, or usefulness of any information, apparatus, product, or process disclosed, or represents that its use would not infringe privately owned rights. Reference herein to any specific commercial product, process, or service by trade name, trademark, manufacturer, or otherwise does not necessarily constitute or imply its endorsement, recommendation, or favoring by the United States Government or any agency thereof. The views and opinions of authors expressed herein do not necessarily state or reflect those of the United States Government or any agency thereof. 
A knowledge of the relationship between $\psi, \theta$, and $\mathrm{K}$ in unsaturated soils is necessary to understand capillary barriers. The two most important relationships are $\psi$ vs $\theta$ and $\psi$ vs $\mathrm{K}$.

Figure 1 is a plot of $\psi$ vs $\theta$ which shows that for a given moisture content the matric potential will be much greater for coarser sand. This means that water has more affinity for the fine sand than

for the coarser material. If the fine layer is placed on top of the coarse layer, the $\psi$ component of the gradient ( $\mathrm{dh} / \mathrm{dz}$ in equation 1 ) will cause upward flow. This upward gradient will exist until the moisture content in the coarse layer is reduced to the point that the matric potentials are equal. Therefore, under unsaturated conditions and neglecting gravity, the moisture content of the fine layer must be much greater than that of the coarse layer in order for flow to occur from the fine to coarse sand. If we include gravity in the analysis, there will still be no flow from the fine to coarse material as long as $(\mathrm{dh} / \mathrm{dz}+1)$ is negative.

PLACE Fig. 1 HERE

The relationship between $\psi$ and $\mathrm{K}$ also illustrates the physical conditions present in a capillary barrier. Figure 2 is a plot of $(\psi)$ vs $\mathrm{K}$ for three sand sizes. It is seen that as matric potential increases, the hydraulic conductivity of the sands decrease and that $\mathrm{K}$ for the 10/20 sand decreases much more rapidly than that of the 100 mesh. The hydraulic conductivity of the 10/20 sand becomes very low as the matic potential increases and becomes an impermeable barrier. By looking at both Figures 1 and 2, it is apparent that the 10/20 sand becomes a barrier to flow when its moisture content is low and the 100 mesh layer is not saturated. It is also apparent that $\mathrm{K}$ becomes very large for the 10/20 mesh sand when the matric potential is small or zero, which corresponds to high moisture content conditions, and instead of being a barrier to flow, the coarse material becomes a channel through which water moves very easily. The barrier characteristics do not become restored until the moisture content of the 10/20 sand drops to significantly.

PLACE Fig. 2 HERE

Air or gas flow through unsaturated porous media exhibits similar, but opposite behavior to that of water. Air permeability, analogous to hydraulic conductivity for water, is a function of moisture content, and thus matric potential. At saturation the gas must displace the liquid present in all pores and thus requires a significant driving force to obtain flow. As the moisture content is reduced, pores in the matrix drain and provide a ready pathway for gas phase movement through the media. Because matric potential is inversely proportional to pore radius the first pores to empty during the desaturation process are the largest. Therefore, air permeability initially increases rapidly as a soil becomes unsaturated, with the rate of increase decreasing quickly with rising matric potential.

The properties of unsaturated porous media have been incorporated in developing capillary barriers. A fine layer of soil placed over a coarse layer could act as a barrier to downward liquid movement if the right conditions existed. For a capillary barrier to function the coarse layer must remain relatively dry, providing a horizon of very low hydraulic conductivity, and the fine layer moisture content has to be below saturation so that breakthrough of liquid into the coarse layer does not occur. These conditions can be met if water is removed from the fine soil before breakthrough occurs.

One method to remove water from the fine layer is to incorporate a sloping interface between the two layers. Water in the overlying fine layer thus should flow downslope out of the system or until the fine soil was nearly saturated and breakthrough occurred. Ross (4) developed an analytical expression that predicted the slope distance at which breakthrough would occur for a given set of conditions under steady-state infiltration. Several problems, which led to failure, were encountered with the initial attempts at using a sloped capillary barrier. These include channeling through the harrier caused by roots and animal burrows, a requirement for steep slopes to convey water to the sides, and finally, if a capillary barrier does fail, it is difficult to dry the coarse layer enough to reinstate the barrier. 
The drying capacity of air circulated through wet soil depends on its specific humidity (W), which is the ratio of the mass of water vapor $\left(m_{\mathrm{v}}\right)$ to the mass of moist air $\left(\mathrm{m}_{\mathrm{a}}\right)$ in the mixture:

$\mathrm{W}=\frac{\mathrm{m}_{\mathrm{v}}}{\mathrm{m}_{\mathrm{a}}}$

The actual specific humidity ( $\left.\mathrm{W}_{\mathrm{act}}\right)$ of air can be calculated from measured relative humidity and temperature. The maximum specific humidity $\left(\mathrm{W}_{\max }\right)$ depends on the vapor pressure of water and is therefore a function of air temperature and atmospheric pressure. The difference between the $\mathrm{W}_{\mathrm{act}}$ and $\mathrm{W}_{\max }$ represents the drying potential of the air (WDP).

$W_{D P}=W_{\max }-W_{\text {act }}$

Figure 3 is a plot of the actual and maximum atmospheric specific humidities for Albuquerque, NM. The drying potential of the air represents the area between the two curves.

PLACE FIG 3 HERE

The soil associated with a dry barrier will have a large thermal mass that will affect the subsurface air temperature, and therefore its drying potential. As a first approximation this analysis will use a constant soil temperature of $13^{\circ} \mathrm{C}$ which is the temperature of soils near Albuquerque. Figure 4 is a plot of the drying power of Albuquerque air adjusted to $13^{\circ} \mathrm{C}$ to reflect subsurface drying of soils.

PLACE FIG. 4 HERE

The most important factor in designing a dry barrier is determining the size and dimensions of the system to circulate dry air through the formation. There are two components to the calculation; determining moisture removal rate and estimating pressure drop through the formation. The moisture removal rate $\left(\mathrm{M}_{\mathrm{H} 2 \mathrm{O}}\right)$ can be calculated using the drying potential $\left(\mathrm{W}_{\mathrm{DP}}\right)$, the volumetric air flow rate $\left(Q_{\text {air }}\right)$ and the density of the air $\left(\rho_{\text {air }}\right)$ :

$\mathrm{M}_{\mathrm{H} 2 \mathrm{O}}=\mathrm{Q}_{\text {air }} \rho_{\text {air }} \mathrm{W}_{\mathrm{DP}}$

The air flow rate through the soil can be calculated from Darcy's Law coupled with the continuity equation. For radial flow of soil gases to a well the pressure drop can be calculated as shown by Johnson et al. (5):

$\frac{\mathrm{Q}_{\mathrm{air}}}{\mathrm{L}}=\pi \frac{\mathrm{k}}{\mu} \mathrm{P}_{\mathrm{w}} \frac{\left(1-\left(\mathrm{P}_{\mathrm{atm}} / \mathrm{P}_{\mathrm{w}}\right)^{2}\right)}{\ln \left(\mathrm{R}_{\mathrm{w}} / \mathrm{R}_{\mathrm{l}}\right)}$

$L$ is the length of the screened interval, $k$ is the intrinsic permeability of the formation, $P_{w}$ is absolute pressure at the well, $P_{a t m}$ is atmospheric pressure, $\mu$ is the viscosity of air, and $R_{W}$ and $R_{l}$ are the radius of the well and the radius of influence respectively. There are four important points to be noted from these equations. First, for a given drying potential (WDP) there is a linear relationship between the air flow rate and the soil moisture removal rate. Second, for a given pressure drop and well spacing there is a linear relationship between the unit air flow rate $\left(Q_{a i r} / L\right)$ and the intrinsic permeability. Third, there is a relatively small dependence on the radius of influence since it is inside the logarithm. Finally, there is a non-linear relationship between air flow and pressure drop in the formation.

\section{DESCRIPTION OF THE DRY BARRIER CONCEPT}

As considered in this project, dry barriers may be used in two different applications; as one component of a multi-layer surface cover for a landfill, or as part of a subsurface containment and remediation system beneath a contaminated zone of soil. Either application would require 
circulation of relatively dry air through the formation to achieve moisture removal. These are described in turn.

Development of A Dry Barrier in a Cover System - One of the priricipal objectives of a landfill cover is to prevent migration of liquids into the underlying waste. The design proposed by EPA (6) consists of a multi-layer cover with a minimum of three layers. The top layer is composed of either topsoil or coarse gravel/cobbles and is intended to promote runoff and prevent erosion. It is underlain by a drainage layer intended to transmit water laterally and which may be comprised of either a geosynthetic or sand material. The bottom layer of the EPA cover is a low permeability layer (hydraulic conductivity less than $10^{-7} \mathrm{~cm} / \mathrm{sec}$ ) designed to minimize infiltration of water through the cover. Optional layers include biological intrusion barriers and gas-vent layers.

Problems with conventional EPA cover tend to appear principally in the compacted soil layer (7). These include compromised integrity from freeze-thaw effects, shrink-swell effects, erosion, subsidence, dessication, root intrusion, and animal intrusion. The alternative to compacted soil layers is use of geosynthetic membranes. These materials are susceptible to construction flaws, tears, and punctures, and do not accommodate large amounts of subsidence and settlement (8). A further concern is possible degradation of the materials, particularly at hazardous and mixed waste sites.

Much recent work has been done on the use of capillary barriers, especially barriers which incorporate vegetative covers to reduce soil moisture to very low levels (9). These barriers include a layer of gravel over the topsoil cover to reduce eroison problems and enhance plant growth. The low moisture content and large pore diameter of material in the coarse layer combine to reduce the hydraulic conductivity of the layer to very low values. Capillary barriers are effective as long as the water content of the fine layer remains low. Large precipitation events or rapid melting of a snow cover can cause a capillary barrier to fail. This has been documented at a pilot demonstration facility at Hill Air Force Base near Salt Lake City, UT (9). Paige et al. (10) provide a comparison of the capillary barriers and EPA cover designs at this site.

A dry barrier incorporated into a cover system offers two potential advantages over conventional caps: 1) reduced water movement through the cover, and 2) more efficient, less costly cover design. Water removal essentially adds an additional component to the water balance of the cover. It is relatively straightforward to incorporate equipment for circulating air through the coarse layers of a conventional cap to form a dry barrier. Air circulating through the coarse formation will also remove some of the moisture in overlying layers, thus increasing its field capacity and reducing potential moisture breakthrough due to unusual precipitation conditions.

A study was conducted to investigate technical and economic feasibility of the dry barrier concept for application in a cover system (11). Two criteria were developed to evaluate potential applicability. The first criterion was the ability of the dry barrier to remove $10 \%$ of annual precipitation. This value, although largely arbitrary, will make a substantial difference in the performance of a landfill cover. Hakonson et al. (9) determined that about $20 \%$ of the annual precipitation was produced as leachate at Hill AFB. A sensitivity analysis using the EPA's HELP model suggested that an average of $16 \%$ of the annual precipitation leaks through the uppermost layers of a cover into the drainage layer.

The second criterion is that the barrier remove moisture equivalent to precipitation during the most vulnerable month. In the Rocky Mountain states the greatest potential for failure occurs during late winter and early spring when evapotranspiration is negligible. Reference to Figure 3 suggests that this is the time of year when ambient air has the greatest drying potential. This second design criteria is considerably more stringent than the first. 
A conceptual design of a dry barrier cover was conducted to evaluate the feasibility of the concept. Design of a dry barrier for a cover application begins by calculating the hydraulics of the system which involves calculating air flow rates, pressure drops, and spacing of the horizontal pipes for directing air flow through the barrier. A plan view illustrating these dimensions for a hypothetical dry barrier is presented in Figure 5. Next, the moisture removal potential of the air must be determined. For the analysis described here this was assumed to be $0.5 \mathrm{~W}_{\max }$, or in other words, a $50 \%$ increase in the relative humidity of the air entering the barrier. Because the average relative humidity in the western US is less than $50 \%$, this assumption is conservative relative to site-specific relative humidity values.

PLACE FIG 5 HERE

The infiltration rate (i) through the top layer of the cover must be estimated as this, coupled with the dryi, 1 , potential determines the amount of air that must be circulated through the barrier to remove water infiltrating over the total area of the barrier $(A)$ :

$\mathrm{M}_{\mathrm{H} 2 \mathrm{O}}=\mathrm{i} \mathrm{A}$

The required air flow rate is found by combining equations (5) and (6). The air flow rates and pressure differentials for various barrier locations is presented in Figure 6.

PLACE FIG 6 HERE

For application of the dry barrier concept to a landfill cover an additional advantage can be gained if the barrier has a large storage capacity. This would allow accumulation of water during a large precipitation event that could be gradually removed over time. Materials such as tuffs which possess dual porosities may be especially suitable. The small intraparticle pores, which give the tuff high primary porosity, also give the material high capacity for water storage. The large interstitial voids between adjacent particles result in high secondary porosity which would give a barrier large intrinsic permeabilities.

Conceptual designs were prepared for a landfill cover in three possible locations, Albuquerque, NM, Los Alamos, NM, and Salt Lake City, UT (11). The dry barriers in Albuquerque and Salt Lake City were designed for worst case infiltration rates, criteria two, so that the design infiltration rates and air flow requirements for a one hectare cover $\left(10,000 \mathrm{~m}^{2}\right)$ calculated from equations (4) and (5) ranged from $1.27 \mathrm{~cm} / \mathrm{mo}$ and $259 \mathrm{~m} 3 / \mathrm{min}$ in Albuquerque to $4.85 \mathrm{~cm} / \mathrm{mo}$ requiring $990 \mathrm{~m}^{3} / \mathrm{min}$ in Salt Lake City. These resulted in a pair of blowers of 100 horsepower and 250 horsepower respectively. It was assumed that the wide availability of tuff for a barrier in Los Alamos would allow design to the less stringent criteria associated with the annual infiltration rate of $4.76 \mathrm{~cm} /$ year. This system required a pair of 30 horsepower blowers.

The only significant design difference between any of the sites was the size of the blower, therefore the capital costs for all three sites, excluding the blower, were the same at approximately $\$ 1000$. These included costs for instrumentation, and piping. Gravel costs were not included as gravel would be required in the landfill cover regardless of the type of barrier chosen. The total capital costs for a one hectare site were estimated at $\$ 27,200$ for a site in Albuquerque, $\$ 10,500$ for a site in Los Alamos, and $\$ 60,900$ in Salt Lake City. The monthly power costs for these systems were $\$ 10,700, \$ 3,200$, and $\$ 53,400$ for sites in Albuquerque, Los Alamos and Salt Lake City respectively.

Development of a Dry Barrier in a Subsurface System - Containment and remediation options for mobile contaminants are extremely limited if the vadose zone beneath the plume is extensive. An extensive recent compilation of technologies for remediation of hazardous waste sites sponsored by USEPA does not include any technologies for remediation of unsaturated soils other than vacuum extraction and its various derivatives, and stabilization/solidification methods (12). Experimental programs are in progress to use horizontal well drilling technology to force different grouting agents into the soil matrix. 
Application of the dry barrier concept to a subsurface contaminant plume is much simpler conceptually in that many of the variables which may be included in the design of a landfill cover are beyond the control of the designer. These include particle size and gradation, overlying and underlying soil properties, and degree of compaction. Many subsurface formations do however have well identified zones of varying permeability, an observation which is particularly relevant for alluvial deposits. Furthermore, formations deeper than three to five meters are not influenced by unusual precipitation events nor by seasonal temperature variations. It is therefore possible to design the system for average conditions of infiltration rate and soil temperature The principle determining factor for determining the feasibility of subsurface dry barrier applications is therefore the ability to circulate air through a formation below the contaminant plume. There are two considerations to be made: 1) identification of a sufficiently permeable strata to enable circulation of dry air beneath the contaminant plume, and 2) the ability to access this strata through use of appropriate drilling technologies.

Traditional field investigations of the hydrogeology associated with a contaminant plume seldom include measurement of the hydraulic properties of soil materials in the vadose zone. However, new developments in vapor extraction technologies have resulted in improved field methods for characterizing unsaturated formations including use of cone penetrometers and air permeability tests. Values for intrinsic permeability range from $1 \times 10^{-13} \mathrm{~m}^{2}(.1$ darcys) for clayey sands to $1 \times 10^{-10} \mathrm{~m}^{2}$ for coarse sands. Johnson et al. (1990) have published an extensive analysis of vapor flow through unsaturated soils which concluded that, except for very low permeability soils, vapor extraction is alternative to conventional remediation techniques.

A site in Santa Fe, NM with a gasoline contamination problem was identified as a candidate site for conducting a feasibility analysis. The stratigraphy at the site consisted of unconsolidated alluvial deposits with the water table located approximately 200 feet beneath the surface. Well logs identified a coarse sand and gravel layer at approximately 40 feet which appeared to extend over the entire area of the spill. The intrinsic permeability of this zone was estimated at $1 \times 10^{-10} \mathrm{~m}^{2}(100$ Darcys). For an average infiltration rate of $3.5 \mathrm{~cm} /$ year (10\% of the annual precipitation rate), a one hectare dry barrier would need to remove $3.5 \times 10^{5} \mathrm{~kg}$ of water to achieve total containment. As with the cover design, a change in relative humidity of $50 \%$ was assumed. If two horizontal wells were installed, each $100 \mathrm{~m}$ long and separated horizontally by $100 \mathrm{~m}$ (i.e. a radius of influence of $50 \mathrm{~m} \mathrm{each}$ ), a total air flow rate of $103 \mathrm{~m} 3 / \mathrm{min}$ would be needed, which would yield a specific air flow rate $(\mathrm{Q} / \mathrm{L})$ of $1.03 \mathrm{~m}^{3} / \mathrm{m}$-min. Equation (5) was used to model the air flow in this system and found a near-linear relationship between the well pressure and flowrate; a specific air flow rate of $1 \mathrm{~m} / \mathrm{m}$-min resulted in a pressure drop of $0.03 \mathrm{~atm}(31 \mathrm{~cm}$ of water column) for a 50 m radius of influence.

Design of a one hectare dry barrier for a subsurface application in Santa Fe, NM would require excavation of two horizontal wells and installation of a blower to inject dry air on one, and a vacuum blower on the other to extract vapor from the formation. The horizontal well construction costs were estimated at $\$ 65,000$ based on a drilling cost of $\$ 55 / \mathrm{ft}$, plus well completion, and mobilization costs. Two 15 horsepower blowers would be required for the air. circulation system at an estimated cost of $\$ 3,500$ each. Piping, installation, and instrumentation costs were estimated at $\$ 15,000$ for a total capital cost of $\$ 87,000$. Annual power costs at $\$ 0.10 / \mathrm{kwhr}$ would be $\$ 19,320$.

An important feature of the subsurface dry barrier application not discussed previously is potential for soil remediation through removal of volatile contaminants. Indeed, soil vapor extraction is an increasingly recognized remediation alternative. A subsurface dry barrier would 
thus provide dual benefits of containing water borne pollutants and removing volatile constituents at the same time.

\section{CONCLUSIONS}

This paper has described an active barrier system formed by circulating dry air through a porous sand or gravel zone. The reduced water content of the zone reduces the hydraulic conductivity to levels comparable to those achievable with compacted clay or geomembranes. The principal mechanism of water removal is through volatilization and advective transport out of the soil. The analyses presented here suggest that there are no engineering obstacles to incorporating a dry barrier into either a landfill cover or as a subsurface barrier beneath a contaminant plume in the vadose zone. Preliminary cost estimates show that in either application a dry barrier has similar costs to those associated with conventional designs, although the operating costs are high. The evaluation of dry barrier technology will next focus on passive dry barrier systems, which use either wind or atmospheric pressure differences to force circulation of air through the barrier.

\section{REFERENCES}

1. JURY, W.A., W.R. Gardner, W.H. Gardner, Soil Physics, John Wiley \& Sons, Inc., New York, NY, 328 p., (1991).

2. HILLEL, D., Introduction to Soil Physics, Academic Press, New York, NY, 364 p., (1980).

3. VAN GENUCHTEN (1980), "A closed-form Equation for Predicting the Hydraulic Conductivity of Unsaturated Soils," Soil Science Society of America, vol. 44, pp. 892898, (1980).

4. ROSS, B., "The Diversion Capacity of Capillary Barriers," Water Resources Research, vol. 26, no. 10, pp. 2625-2629, (1990).

5. JOHNSON, P.C., C.C. Stanley, M.W. Kemblowski, D.L. Byers, J.D. Colthart, "A Practical Approach to the Design, Operation, and Monitoring of In Situ Soil-Venting Systems," Ground Water Mon. Rev., vol. 10, no. 2, pp. 159-178, (1990).

6. US ENVIRONMENTAL PROTECTION AGENCY, Design and Construction of RCRA/CERCLA Covers, Seminar Publication, EPA/625/4-91/025, USEPA, Washington, DC, (1991)

7. SUTER, G.W., R.J. Luxmoore, E.D. Smith, "Compacted Soil Barriers at Abandoned Landfill Sites are Likely to Fail in the Long Term," J. of Environ. Qual., vol. 22, pp. 217. 226, (1993).

8. OWEIS, I.S., "Sanitary Landfill Clay Caps: Do They Inhibit Leachate Generation?" J. of Resource Mgt. and Tech., vol. 17, no. 3, (1989).

9. HAKONSON, T.E., K.L. Manies, R.W. Warren, K.V. Bostick, G. Trujillo, J.S. Kent, L.J. Lane, "Migration Varrier Covers for Radioactive and Mixed Waste Landfills," Proc. of ER Tech. Transfer, USAF Center for Environ. Excellence, (Jan. 26-28, 1992).

10. PAIGE, G., T.E. Hakonson, D.S. Yakowitz, L.J. Lane, J.J. Stone, "A Prototype Decision Support System forthe Evaluation of Shallow Land Disposal Trench Cap Designs," DOE ER 93 Environ. Remed. Conf., (Oct. 24-28, 1993).

11. STORMONT, J.C., M.D. Ankeny, M.E. Burkhard, M.K. Tansey, J.A. Kelsey, "Assessment of An Active Dry Barrier For a Landfill Cover System," report to US Dept. of Energy, Office of Technology Development, Sandia National Labs., Albuquerque, NM, (1993).

12. GRASSO, D., Hazardous Waste Site Remediation: Source Control, Course Pack, Univ. of Conn., US Environ. Prot. Agency, Storrs, CN, (1993). 


$$
\begin{aligned}
& \mathrm{J}_{\mathrm{W}}=-\mathrm{K}(\psi)\left(\frac{\partial \mathrm{h}}{\partial \mathrm{z}}+1\right) \\
& \mathrm{W}=\frac{\mathrm{m}_{\mathrm{v}}}{\mathrm{m}_{\mathrm{a}}} \\
& \mathrm{W}_{\mathrm{DP}}=\mathrm{W}_{\max }-\mathrm{W}_{\mathrm{act}} \\
& \mathrm{M}_{\mathrm{H} 2 \mathrm{O}}=\mathrm{Q}_{\text {air }} \rho_{\text {air }} \mathrm{W}_{\mathrm{DP}} \\
& \left.\mathrm{Q}_{\text {air }} \mathrm{L}\right)=\pi \frac{\mathrm{k}}{\mu} \mathrm{P}_{\mathrm{w}} \frac{\left(1-\left(\mathrm{P}_{\mathrm{atm}} / \mathrm{P}_{\mathrm{w}}\right)^{2}\right)}{\ln \left(\mathrm{R}_{\mathrm{w}} / \mathrm{R}_{1}\right)}
\end{aligned}
$$

$\mathrm{M}_{\mathrm{H} 2 \mathrm{O}}=\mathrm{i} A$ 


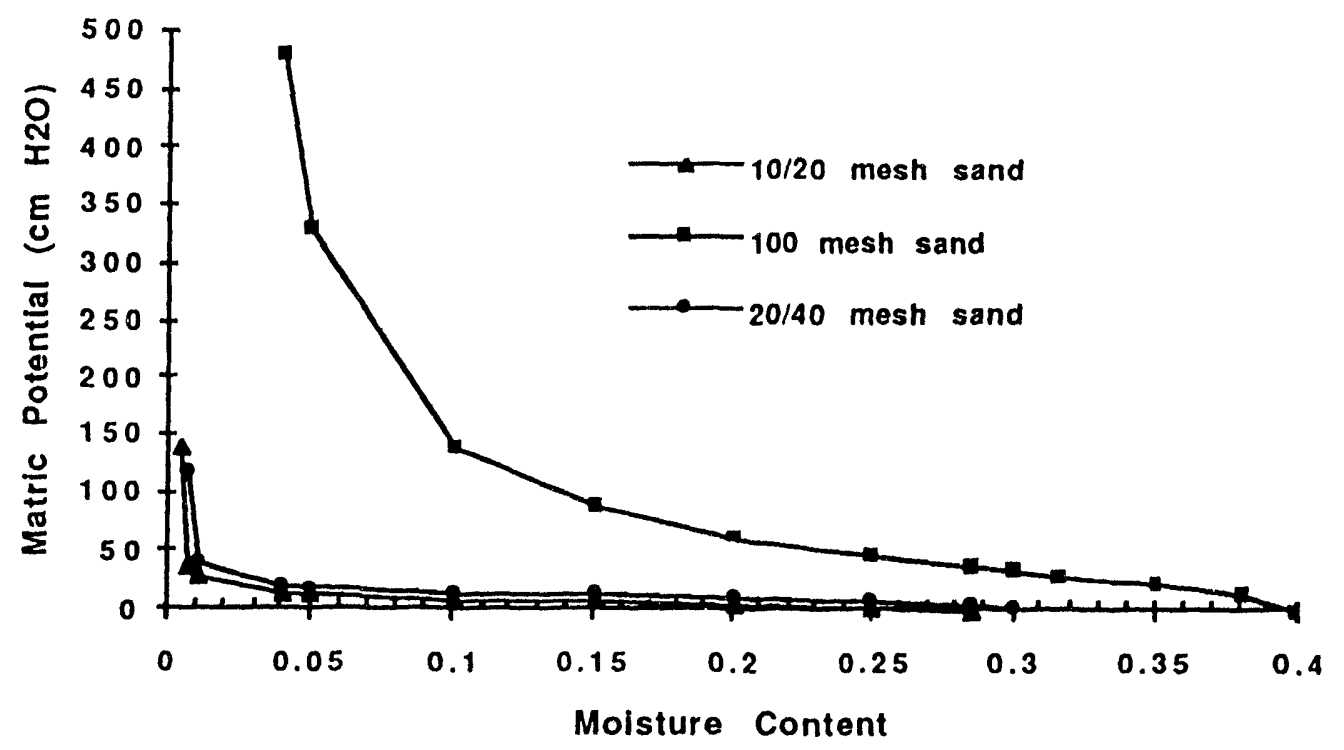

Fig. 1. Matric potential versus moisture content for three sand sizes.

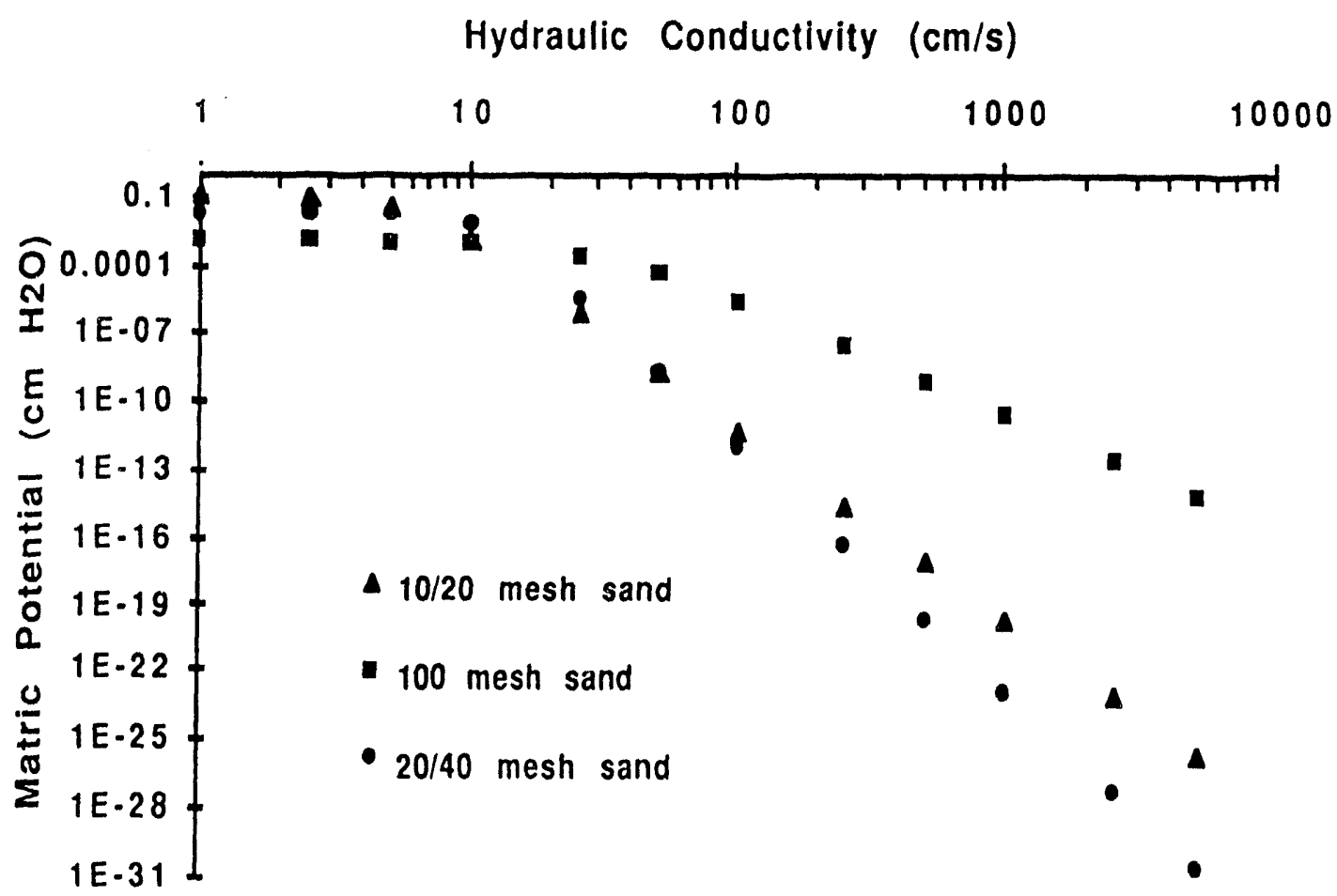

Fig. 2. Matric potential versus hydraulic conductivity for three sand sizes. 


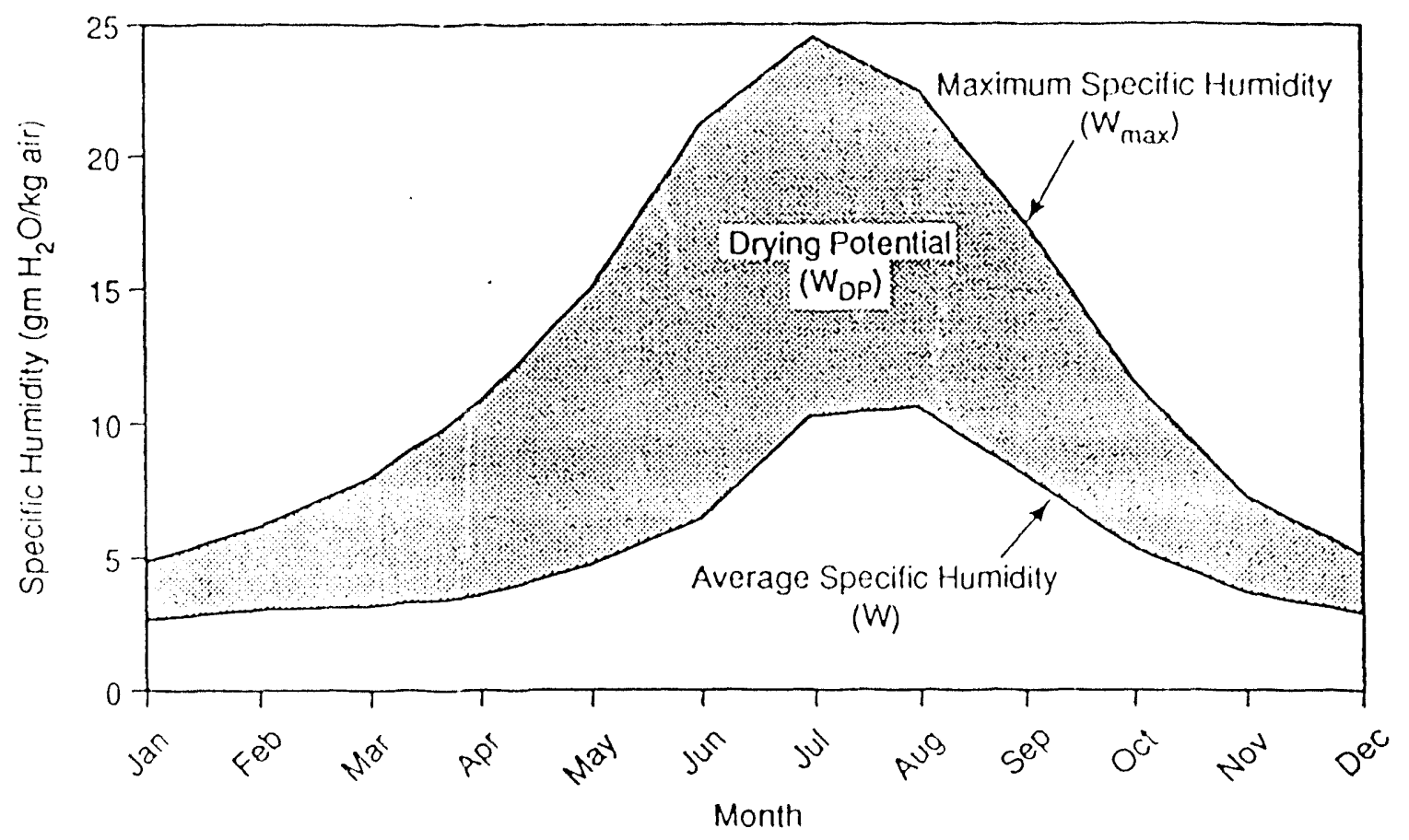

Fig. 3. Drying potential of Albuquerque air in terms of specific humidity (11).

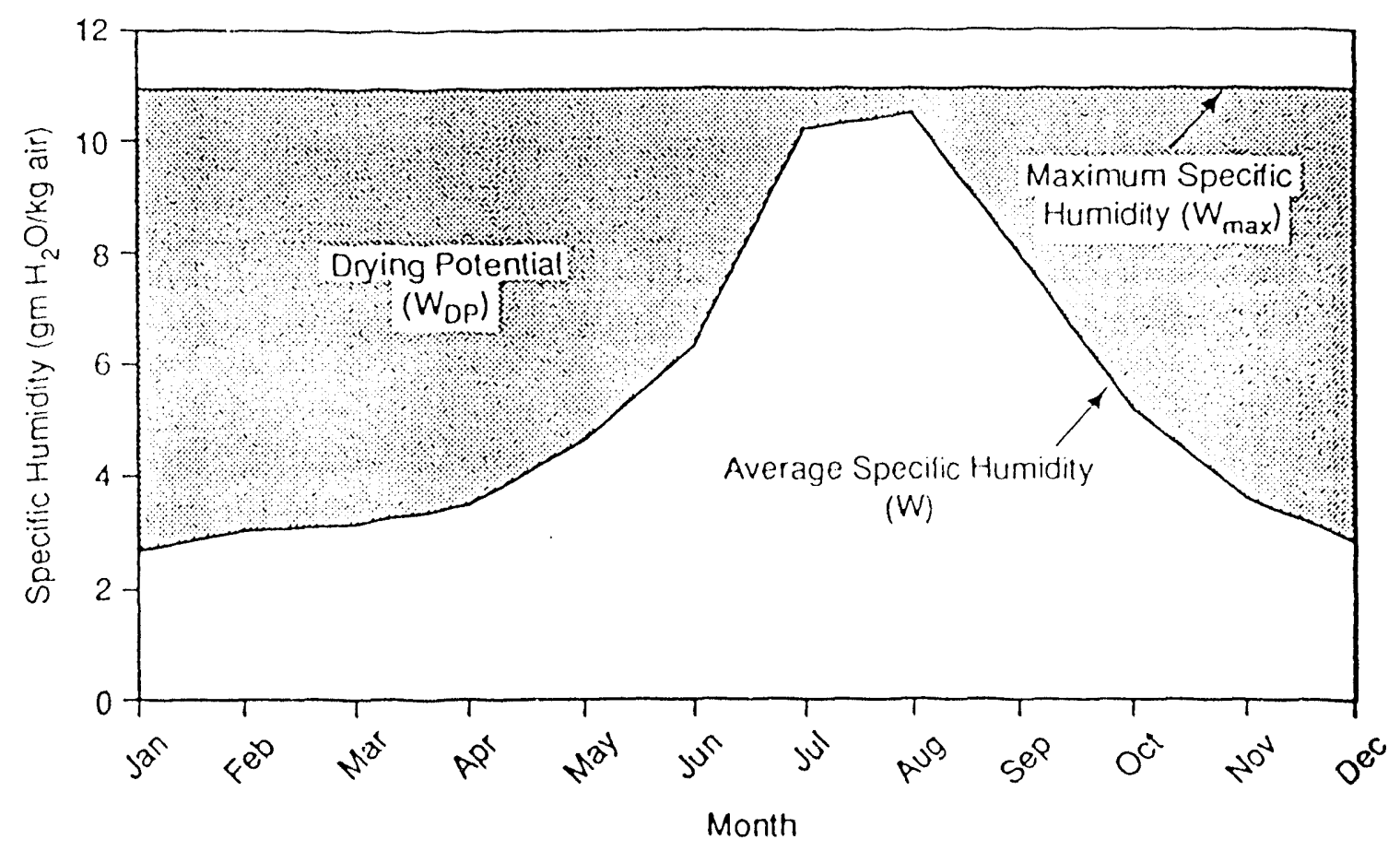

Fig. 4. Drying power of air equilibrated with $13^{\circ}$ soil in terms of specific humidity (11). 


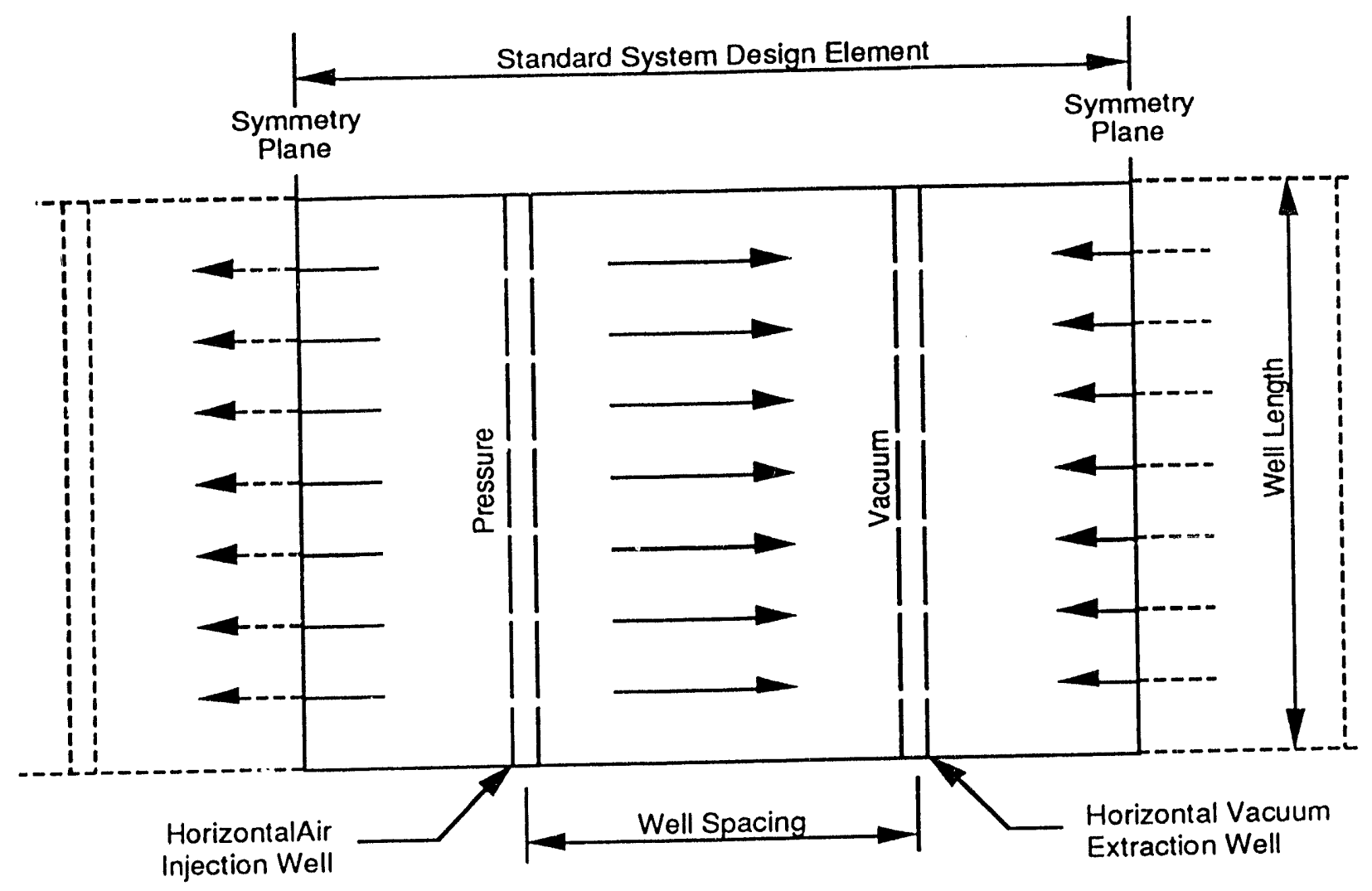

Fig. 5. Plan view of a dry barrier design showing piping configuration in the coarse layer.

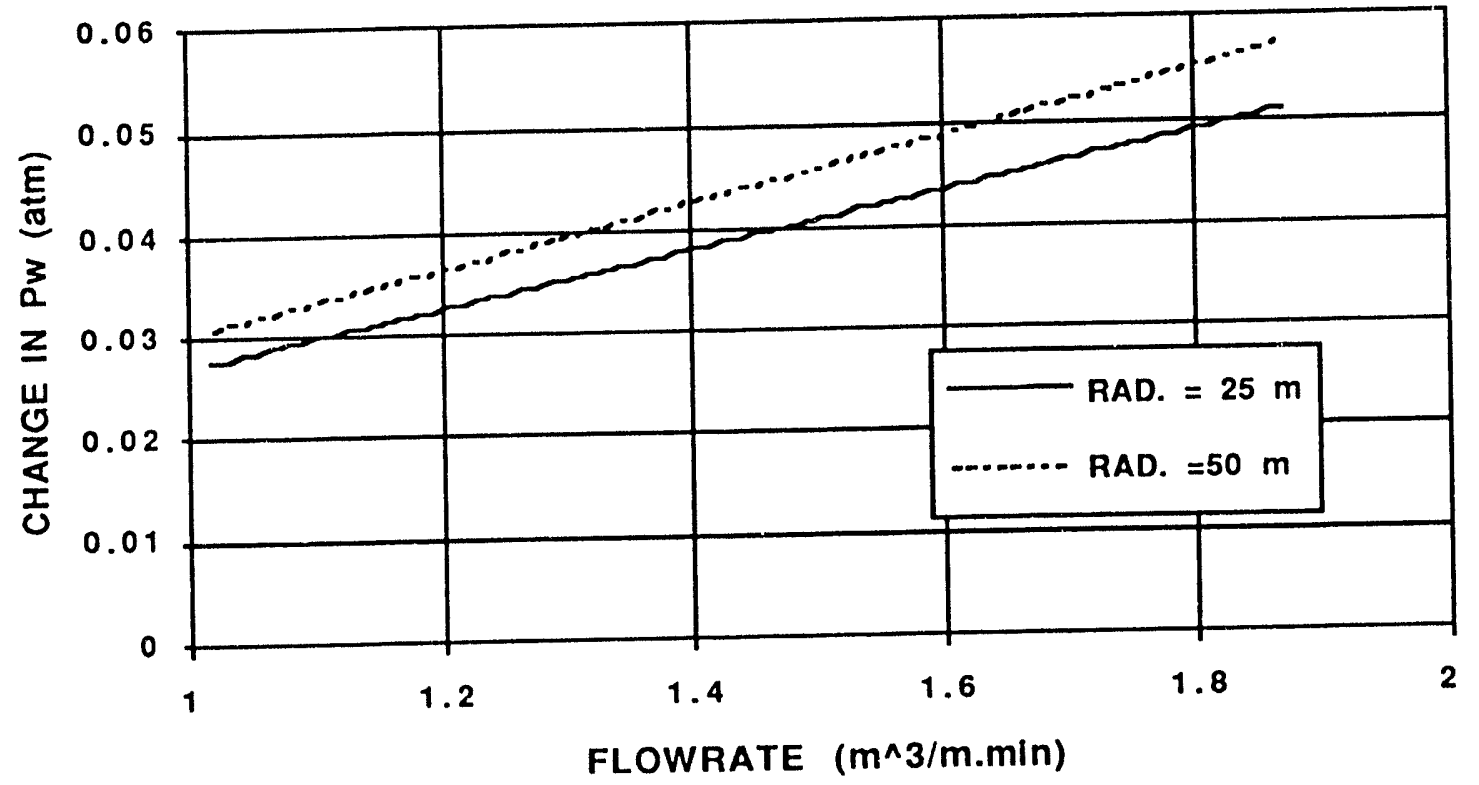

Fig. 6. Differential pressures versus air flow rates for two ditferent radii of influence (intrinsic permeability $=100$ darcys). 

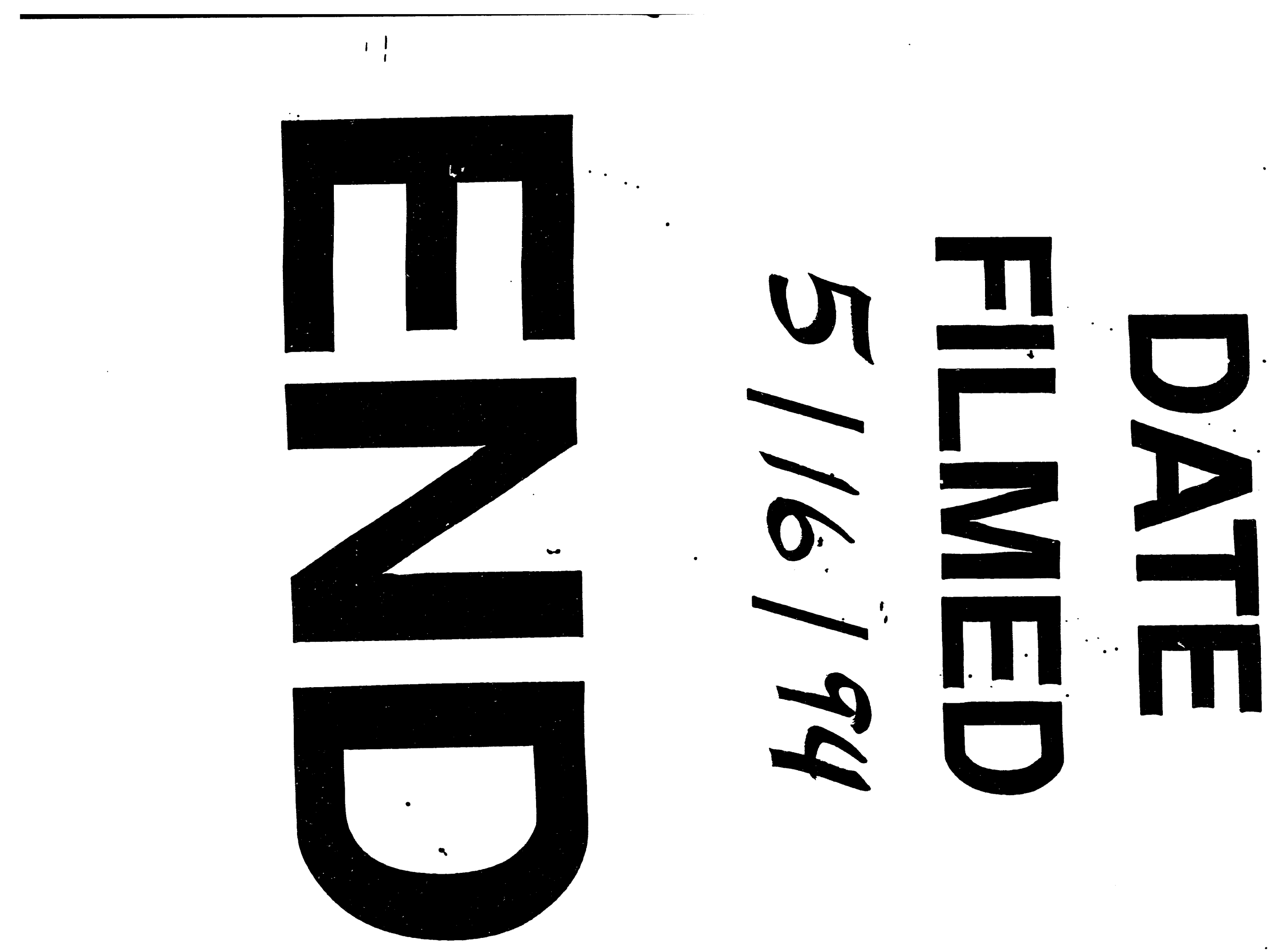

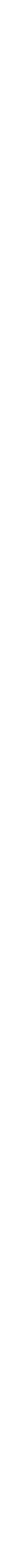

(1) 